Results The factorial analyses indicated a two-dimensional structure (perception of work ability/mental resources and diseases and health restrictions). The value of Cronbach's $\alpha$ and McDonald $\omega$ was, respectively, 0.80 and 0.87 . The theoretical hypothesis of the construct validity were confirmed with direct correlation and significant of the WAI with the scores of reward, control and selfevaluate of the health status; inverse correlation and significant with the scale of need for recovery, psychological distress, effort, overcommitment and demand.

Conclusion We found good evidence for a high reliability and construct validity of WAI questionnaire, supporting its use in future analyses in similar populations.

\section{SP6-12 THE HEALTH AND WELL-BEING OF LAID-OFF AUTOMOBILE INDUSTRY WORKERS IN DURHAM, CANADA}

doi:10.1136/jech.2011.142976p.83

E Bartfay, ${ }^{*}$ W Bartfay, T Wu. University of Ontario Institute of Technology, Oshawa, Ontario, Canada

Introduction The City of Oshawa in Durham, Canada is a major manufacturing hub for automotive production. In 2008-2009, we witnessed an unprecedented economic crisis not seen since the great depression. A record number of auto-workers lost their jobs as a result. Little is known about how these lay-offs affected the health and well-being of the workers. This exploratory study examined the impact of being laid-off on the emotional, physical, social and financial health of auto-workers.

Methods A purposive sampling technique was employed to recruit participants from two locations: The CAW Community Action Centre and a Service Fair organised by the Durham Region Local Training Board. All participants were asked to complete an in-depth demographic and health questionnaire.

Results A total of 36 laid-off workers were interviewed between 28 October and 30 November 2009. Approximately two-third of our participants were male and the mean age was $45(\mathrm{SD}=6$, range $=30-61)$. The average length of time since laid-off was 13 months $(S D=8$, range $=1-36)$. Half of our participants reported a feeling of burden to others and a loss of social status, and $75 \%$ reported a loss of identity and pride. With regard to the self-rated health and well-being status on a scale of 1 (very poor) to 5 (excellent) since being laid-off, our participants reported mid-level physical health $($ score $=3.12$ ), but relatively poor emotional health (score $=2.59)$, social health $($ score $=2.5)$ and financial health (score $=1.97$ ).

Conclusion Job loss can have a wide range of effect on one's wellbeing, including physical, emotional, social and financial health.

\section{SP6-13 SLEEP DURATION AND OVERWEIGHT IN EUROPEAN CHILDREN: IS THE ASSOCIATION MODIFIED BY GEOGRAPHIC REGION?}

doi:10.1136/jech.2011.142976p.84

${ }^{1} \mathrm{~S}$ Hense, ${ }^{*}{ }^{2} \mathrm{~S}$ De Henauw, ${ }^{3} \mathrm{G}$ Eiben, ${ }^{4} \mathrm{D}$ Molnar, ${ }^{5} \mathrm{~L}$ A Moreno, ${ }^{6} \mathrm{G}$ Barba, ${ }^{7} \mathrm{C}$ Hadjigeorgiou, ${ }^{8} \mathrm{~T}$ Veidebaum, ${ }^{1} \mathrm{H}$ Pohlabeln, ${ }^{1} \mathrm{~W}$ Ahrens. ${ }^{1}$ Division of Epidemiological Methods and Etiologic Research, Bremen Institute for Prevention Research and Social Medicine (BIPS), Bremen, Germany; ${ }^{2}$ Department of Public Health/Department of Movement and Sport Sciences, Faculty of 3Medicine and Health Sciences, Ghent University, Ghent, Belgium; 'Department of Paediatrics, Queen Silvia Children's Hospital, Goteborg University, Goteborg, Sweden; ${ }^{4}$ Department of Paediatrics, Medical Faculty, University of Pécs, Pécs, Hungary; ${ }^{5}$ Growth, Exercise, Nutrition and Development (GENUD) Research Group, E.U. Ciencias de la Salud, University of Zaragoza, Zaragoza, Spain; ${ }^{6}$ Unit of Epidemiology \& Population Genetics, Institute of Food Sciences, National Research Council, Avellino, Italy; ${ }^{7}$ Research and Education Institute of Child Health, Strovolos, Cyprus: ${ }^{8}$ National Institute for Health Development, Tallin Estonia

Introduction An association between sleep duration and overweight has been reported from several countries. Comparability of those results is limited by reasons of methodological differences. In a multi-center study we analysed this association in children from northern and southern Europe.

Objectives To investigate differences and a possible effect modification by geographical region in the association between sleep duration and overweight.

Methods In the IDEFICS-Study we examined 16.223 children (2-9 years) from eight European countries. Sleep was assessed by means of a parental 24h-Recall. Logistic regression models were applied to analyse the association between overweight and sleep duration and to test for effect modification by region.

Results A dose dependent association between sleep duration and overweight was seen. This persisted after adjustment, but remained significant only for sleeping $<9 \mathrm{~h}$ if stratified by region (north:OR $2.0 ; 99 \%$ CI 1.3 to 3.2 vs south:OR 2.5 ; $99 \%$ CI 1.4 to 4.3 ). No effect modification by region was found. The association was stronger in older children.

Conclusion Geographic region and related aspects do not modify the association between sleep and overweight, but should be taken in consideration as a confounding factor on this association.

\section{SP6-14 SLEEP DURATION AND HEALTH STATUS ASSESSMENT IN BRAZILIAN ELDERLY. A POPULATION BASED STUDY (ISACAMP 2008/09)}

doi:10.1136/jech.2011.142976p.85

M G Lima, M B A Barros. * State University of Campinas, UNICAMP, Campinas, São Paulo, Brazil

Objective The aim of this study was to assess the association of sleep duration with health status or health related quality of life (HROL), according to gender, in non-institutionalised elderly population living in Campinas (Brazil).

Methods It is a population-based cross-sectional study developed using data from the Campinas Health Survey carried out in 2008/ 2009. The SF-36 v2 health survey was used to assess the HROL of 1520 elderly individuals. The eight scales of SF-36 and the physical and mental component summary measures were the dependent variables and the principal independent was sleep duration. Simple and multiple linear regression models were used to verify the association among the variables.

Results The sleep duration of 5 or fewer hours was associated with poor health status only in the female population, in the mental component of HROL. Sleeping $10 \mathrm{~h}$ or more was associated with the eight SF-36 scales and two components, in the elderly male population. In the female, only the physical function, role physical, mental health dimensions were associated with this sleep duration. Conclusion HROL was associated only with the long sleep in the elderly men. In women, both the short and long sleep was associated negatively with the health status, in different dimensions. Considering that health self-assessment has a significant relationship with clinical status and mortality, research on health related quality of life and sleep duration become important, and this study is among the first to present this relationship.

\section{SP6-15 FETAL AUTOPSY AND INFORMATION QUALITY OF DEATH CERTIFICATES}

doi:10.1136/jech.2011.142976p.86

${ }^{1} \mathrm{M} F$ de Almeida, ${ }^{* 1} \mathrm{G}$ P de Alencar, ${ }^{1} \mathrm{D}$ Schoeps, ${ }^{1} \mathrm{E}$ Minucci, ${ }^{1} \mathrm{Z}$ P da Silva, ${ }^{1} \mathrm{~L}$ P Ortiz, ${ }^{1} \mathrm{H}$ M D Novaes, ${ }^{1} \mathrm{D}$ Schout, ${ }^{1} \mathrm{~A}$ P de Alencar, ${ }^{1} \mathrm{P}$ Raspantini, ${ }^{1} \mathrm{P}$ Santos. ${ }^{1}$ University of 